\title{
Restricted Structural Change and the Unit Root Hypothesis
}

\author{
David H. Papell and Ruxandra Prodan \\ University of Houston and University of Alabama
}

March 2005

In a classic paper, Nelson and Plosser (1982) could not reject the unit root hypothesis in favor of trend stationarity for 13 out of 14 long-term annual macro series. Subsequent studies, allowing for one or two structural changes, have found more rejections with a broken trend stationary alternative. Since these changes are defined to be permanent, the rejections do not provide evidence of trend stationarity. We propose new tests for a unit root in the presence of restricted structural change. Allowing for two offsetting structural changes, we reject the unit root null in favor of restricted trend stationarity at the $5 \%$ significance level for 6 out of 13 series.

\section{Correspondence to:}

David Papell, Department of Economics, University of Houston, Houston, TX 77204-5019, email: dpapell@mail.uh.edu

Ruxandra Prodan, Department of Economics, University of Alabama, Tuscaloosa, Al, 35487, email: pprodan@cba.ua.edu 


\section{Introduction}

An important issue in economics involves the long-run response of macroeconomic and financial aggregates to shocks and disturbances. In a classic paper, Nelson and Plosser (1982) argued that, contrary to the traditional view, current shocks have permanent effects on the long-run level of macroeconomic time series. Using statistical techniques developed by Dickey and Fuller (1979), they found evidence in favor of unit roots for 13 out of 14 long-term annual macro series, the only exception being the unemployment rate. They conclude that these series behave more like a random walk than like transitory deviations from a steadily growing trend.

Nelson and Plosser's findings of a unit root have been called into question on a number of grounds. Rudebusch $(1992,1993)$ demonstrates that unit root tests have low power against estimated trend stationary alternatives. Moreover, he shows that if trend stationary models are correct, difference stationary models do not yield good approximations to the medium-term dynamic response. Perron (1989) questions the ability of unit root tests to distinguish unit root from stationary processes that contain segmented or shifted trends. Incorporating an exogenous break point and specifying 1929 as the break date, he found evidence of broken trend stationarity for 10 out of the 13 series.

Perron's analysis was disputed by several papers, most notably Christiano (1992), Banerjee et al. (1992), and Zivot and Andrews (1992). These authors argued that it is inappropriate to specify the break date as known, as it is not reasonable to believe that the choice has been made independently of the data? They suggest that an appropriate procedure is to select the break date endogenously. In particular, Zivot and Andrews (1992), using a data-dependent algorithm to determine the breakpoint and finite-sample critical values, reject the unit root null at the 5\% significance level for only three out of 13 Nelson-Plosser

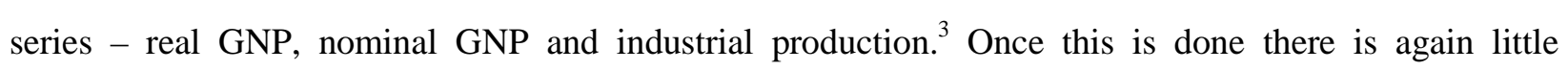
evidence against the unit root hypothesis. Allowing for two endogenous breaks, Lumsdaine and Papell (1997) re-examine the unit root hypothesis for the Nelson-Plosser data. Using finite-sample critical values, they reject the unit root null for 5 series, the three series found by Zivot and Andrews plus percapita real GNP and employment, therefore finding more evidence against unit roots than Zivot and Andrews.

These studies reject the unit root hypothesis in favor of broken trend stationarity for macroeconomic aggregates, but not for prices or financial variables. This seems to confirm not only the

\footnotetext{
${ }^{1}$ Others, including Campbell and Mankiew (1987) and Cochrane (1988) have argued that current shocks are a combination of temporary and permanent shocks and that the long-run response of a series to a current shock depends on the relative importance or "size" of the two types of shocks.

${ }^{2}$ Because the exogenously chosen point is assumed to be estimated without error, the critical values are biased in favor of rejecting the unit root null hypothesis.
} 
common practice of macroeconomists to model movements in real GNP as stationary fluctuations around a linear deterministic trend (Kydland and Prescott, 1980; Blanchard, 1981) but also previous analyses, which had advanced the unit root hypothesis for the velocity of money (Gould and Nelson, 1974) and stock prices (Samuelson, 1973).

Results of the previous studies show that for many of the aggregate time series the estimated breaks coincide with World Wars or the Great Depression. Standard macroeconomic theory, however, argues that while these events have long-lasting transitory effects, they do not have permanent effects on aggregate variables. The decline in output associated with the Great Depression has generally been interpreted as a temporary response to a significant reduction in the money stock (Friedman and Schwartz, 1963) and the substantial increase in output that occurred during World War II is described as the result of the huge temporary increase in government purchases caused by the war (Barro, 1981).

Murray and Nelson (2000), studying long-term real GDP data, argue that the fluctuations of 1930-1946 seem to have had a temporary effect on the level of output and lead to rejections of the unit root hypothesis when it is true. ${ }^{-}$Murray and Nelson (2002) quantify models where the effects of wars and depressions can be interpreted as transitory, based on a parametric bootstrap of a Markov switching model for real GDP from 1870-1994. Kilian and Ohanian (2002), using the annual per-capita GNP series of Nelson and Plosser, suggest that unit root tests against trend-break alternatives, as in Zivot and Andrews (1992), are not able to correctly identify transitory movements in endogenous variables. They conclude that these tests mistakenly interpret a random walk with drift and occasional large transitory changes as being trend stationary with a permanent change.

Previous work can be categorized into three hypothesis: The Nelson and Plosser hypothesis is that all changes are permanent; the Perron hypothesis is either that one change, The Great Depression, is permanent and all others are transitory or that two changes among The Great Depression, World War I and World War II are permanent and all others are transitory; and the Murray and Nelson hypothesis is that one change, The Great Depression, is transitory and all others are permanent. In this paper, we propose a new hypothesis: the restricted structural change hypothesis. We restrict the underlying process to trend stationarity, allowing for two offsetting structural changes. Under this hypothesis, the structural change, although potentially long-lasting, is ultimately reversed. In contrast to Perron, Zivot and Andrews

\footnotetext{
${ }^{3}$ Using asymptotic critical values, they reject the unit root null for three more series. These critical values, however, are biased towards rejecting the null in finite samples. We therefore limit our comparisons to the results obtained using finite-sample critical values that incorporate the temporal dependence in the data.

${ }^{4}$ They find that when a temporary component is added to the level of a unit root process, in the form of a one period outlier or a short-lived AR, rejections of the unit root hypothesis occur with high probability and structural breaks are indicated when none occurs.

${ }^{5}$ Beaudry and Koop (1993) and Kim and Nelson (1999) argue that fluctuations are asymmetric, negative innovations to GNP (as recessions) being transitory and positive shocks being amplified overtime.
} 
and Lumsdaine and Papell, where the alternative hypothesis is broken trend stationarity, the alternative, as in Nelson and Plosser, is consistent with trend stationarity.

We focus on the Nelson and Plosser data for 1909-1970 because it has been previously analyzed by numerous authors and it is central to a number of macroeconomic issues. We develop three versions of the tests: one that incorporates restrictions on the shifts in the intercept, a second that incorporates restrictions on the shifts in the intercept and the slope of the trend function, and lastly a version that incorporates restrictions on the shifts in the intercept and the slope of the trend function corresponding to the first break and the slope corresponding to the second break. We reject the unit root null in favor of restricted trend stationarity, at the 5\% significance level, for 6 out of 13 series. Using restricted structural change tests, we obtain stronger rejections with a more restrictive alternative hypothesis than Lumsdaine and Papell, who show evidence of broken-trend stationarity for 5 series at the 5\% significance level. In accord with previous research, we generally reject unit roots for macroeconomic aggregates but do not reject unit roots for prices or financial variables.

The point of this paper, however, is not simply to argue that we can reject the unit root null in 6 instead of 5 cases. In order to evaluate the economic significance of our results, we perform simulations to evaluate the power of our tests. First we conduct a Monte Carlo experiment to determine the behavior of the unit root tests when the data generating process is consistent with the Perron hypothesis: broken trend stationary with one break or two breaks that occur in the same direction. We find that, while the appropriate tests for a unit root in the presence of unrestricted structural change have good power, our tests for a unit root in the presence of restricted structural change have very low power. In this case, low power is a desirable attribute. Broken trend stationary processes will not be mistakenly interpreted by tests for a unit root in the presence of restricted structural change as trend stationary.

In our next simulation experiment we consider the 6 series where we reject the unit root null using one or more restricted structural change model(s). We examine simulated data from these models and study the empirical distribution of the test statistic implied by the fitted models. Our simulation results show that, while the restricted tests have very high power on data that includes restricted structural change, the unrestricted tests also have good power. Restricted structural change processes, therefore, can be mistakenly interpreted by tests for a unit root in the presence of structural change as broken trend stationary. The simulation analysis also allows us, in some cases, to choose among models. For 4 of the 6 series, the unit root null can be rejected in favor of the restricted trend stationary alternative with more than one model. We can associate a specific restricted structural change model to a series in 2 of these 4 cases.

The view that, although macroeconomic variables have unit roots, they also are characterized by substantial transitory fluctuations is not explicitly modeled by testing the null of a unit root against a 
restricted trend stationary alternative. In line with previous literature, we study the rejection frequencies of our restricted tests for data that are consistent with the Murray and Nelson hypothesis: transitory fluctuations from The Great Depression and World War II as well as a random-walk component. We find that our restricted unit root tests that allow only for intercept changes are not biased towards rejection of the unit root null in this specific case. Restricted unit root tests that allow for intercept and slope changes do not behave as well, especially when the ratio between the variance of the stationary and the nonstationary components becomes large.

\section{Unit Root Tests with a Restricted Structural Change Alternative}

Much research has been conducted on testing for unit roots in the presence of a one-time change in the mean, trend, or both the mean and the trend of economic time series. Under the Perron hypothesis, the one-time change in the trend function is permanent because, by definition, a one-time change cannot be reversed. Failure to reject the unit root null against a trend stationary alternative, as in Nelson and Plosser (1982), combined with rejection of the unit root null against a broken trend stationary alternative, as in three of the Zivot and Andrews (1992) series, would be interpreted as evidence of a one-time permanent change. In Lumsdaine and Papell (1997), the two structural changes are treated as permanent. While rejection of the unit root null in favor of the two-break alternative is generally interpreted as evidence of broken trend stationarity, this interpretation is not necessarily correct. Suppose that the series is subject to two changes in the trend function. If the changes are offsetting, the series is trend stationary. If the changes are not offsetting, either because they act in the same direction or because they act in opposite directions but are of different magnitude, the series is broken trend stationary.

We implement the restricted structural change hypothesis by, in the context of unit root tests that allow for two breaks, restricting the coefficients on the dummy variables that depict the breaks to produce a long-run constant trend. The trend function following the third break is constrained to be a linear projection of the trend function preceding the first break, exactly as if there were no breaks. In contrast with previous tests for unit roots in the presence of structural change, where the alternative hypothesis is broken trend-stationarity, our alternative hypothesis is consistent with trend-stationarity.

\subsection{Construction of restricted tests for a unit root}

We first consider three models under the alternative hypothesis: model AA that allows for two

\footnotetext{
${ }^{6}$ While Lumsdaine and Papell (1997) do not consider the possibility of offsetting structural changes, they are not ruled out by their methodology.

7 Papell and Prodan (2005) develop tests for a unit root in the presence of restricted structural change in order to test for long-run Purchasing Power Parity. They use additive outlier models and only allow for changes in the intercept.
} 
changes in the intercept of the trend function; model CC that allows for two changes in the intercept and the slope of the trend function; and model CB that allows for a change in the intercept and slope of the trend function for the first break and a change in the slope of the trend function for the second break. In the absence of restrictions, models AA and CC are exactly those estimated by Lumsdaine and Papell (1997) which, in turn, are two-break extensions of the models in Zivot and Andrews (1992). Next we impose restrictions in order to assure the alternative of trend stationarity. Following, we describe these models in detail:

Model AA: $\quad \Delta y_{t}=\mu+\beta t+\gamma_{1} D U 1_{t}+\gamma_{2} D U 2_{t}+\alpha y_{t-1}+\sum_{i=1}^{k} c_{i} \Delta y_{t-i}+\varepsilon_{t}$

For $\mathrm{t}=1, \ldots, \mathrm{T}$, where $\mathrm{c}(\mathrm{L})$ is a lag polynomial of known order $\mathrm{k}$ and $1-\mathrm{c}(\mathrm{L}) \mathrm{L}$ has all its roots outside the unit circle, $\mathrm{DU} 1_{\mathrm{t}}$ and $\mathrm{DU} 2_{\mathrm{t}}$ are indicator dummy variables for the intercept changes in the trend function, occurring at times $\mathrm{TB}_{1}$ and $\mathrm{TB}_{2}$. That is, DU1 $=1\left(\mathrm{t}>\mathrm{TB}_{1}\right)$ and DU2 $=1\left(\mathrm{t}>\mathrm{TB}_{2}\right)$.

The alternative becomes restricted trend stationarity with the addition of the following constraint:

$$
\gamma_{1}+\gamma_{2}=0
$$

Since the coefficients on the breaks are of equal and opposite sign and the slope does not change, the trend following the second break is restricted to equal the trend prior to the first break.

Equation (1) is estimated sequentially for each break year $T b i=\mathrm{k}+2, \ldots, \mathrm{T}-2$, where $\mathrm{i}=1,2$ and $\mathrm{T}$ is the number of observations, $T b_{1} \neq T b_{2}$ and $T b_{1} \neq T b_{2} \pm 1$. We use the general-to-specific recursive t-statistic procedure suggested by $\mathrm{Ng}$ and Perron (1995) to choose the number of lags. We set the maximum value of $\mathrm{k}$ equal to 8 , and use a critical value of 1.645 from the asymptotic normal distribution to assess significance of the last lag. The null hypothesis of a unit root without structural change is rejected in favor of the alternative hypothesis of trend-stationarity with restricted structural change if $\alpha$ is significantly different from 0 in Equation (1). The chosen break is that for which the maximum evidence against the unit root null, in the form of the most negative t-statistic on $\alpha$, is obtained.

In order to consider series which experience not only changes in the intercept but also changes in the slope of the trend function we will consider two additional models:

Model CC: $\Delta y_{t}=\mu+\beta t+\gamma_{1} D U 1_{t}+\theta_{1} D T 1_{t}+\gamma_{2} D U 2_{t}+\theta_{2} D T 2_{t}+\alpha y_{t-1}+\sum_{i=1}^{k} c_{i} \Delta y_{t-i}+\varepsilon_{t}$

for $\mathrm{t}=1, \ldots ., \mathrm{T}$. In addition to model AA, DT $1_{\mathrm{t}}$ and $\mathrm{DT} 2_{\mathrm{t}}$ are the corresponding changes in the slope of the trend function. That is $\mathrm{DT} 1_{\mathrm{t}}=\left(\mathrm{t}-\mathrm{TB}_{1}\right) 1\left(\mathrm{t}>\mathrm{TB}_{1}\right)$ and $\mathrm{DT} 2_{\mathrm{t}}=\left(\mathrm{t}-\mathrm{TB}_{2}\right) 1\left(\mathrm{t}>\mathrm{TB}_{2}\right)$.

\footnotetext{
${ }^{8}$ We do not use tests for a single break model or model CA (which allows for one change in the intercept and the slope followed by a change in the intercept of the trend function) because we cannot impose restrictions in order to produce trend-stationarity. For instance, in the case of model CA, the change in the slope corresponding to the first break cannot be reverted to the trend.
} 
In this case, the unit root test becomes a test for restricted trend stationarity with the addition of two restrictions:

$$
\theta_{1}+\theta_{2}=0
$$

which imposes a constant trend following the second break, as well as prior to the first break, and

$$
\gamma_{1}+\gamma_{2}+\theta_{1}\left(T b_{2}-T b_{1}\right)=0
$$

this restricts the trend following the second break to equal the trend prior to the first break. We follow the same procedure as before to choose the breaks and to test the unit root hypothesis.

Whether the effects of the Great Depression are permanent or transitory is central to the hypotheses described above. We propose a new model, $\mathrm{CB}$, which captures the idea that the aggregates fell during The Great Depression (a change in the intercept and the slope for the first break), followed by a smooth transition once the trend is re-attained (a change in the slope, but not the intercept, for the second break).

Model CB: $\Delta y_{t}=\mu+\beta t+\gamma_{1} D U 1_{t}+\theta_{1} D T 1_{t}+\theta_{2} D T 2_{t}+\alpha y_{t-1}+\sum_{i=1}^{k} c_{i} \Delta y_{t-i}+\varepsilon_{t}$

As in model CC, we impose a constant trend following the second break, as well as prior to the first break, as described by Equation (4), and we also restrict the trend following the second break to equal the trend prior the first break.

$$
\gamma+\theta_{1}\left(T b_{2}-T b_{1}\right)=0
$$

\subsection{Calculation of critical values for the unit root tests}

Due to the various sizes of the series and the temporal dependence in different data sets, asymptotic critical may often substantially differ from appropriate finite-sample critical values and lead to biased rejections. Using Monte Carlo methods, we compute finite-sample critical values for our test statistics, under specific distributional assumptions. For each series, we first assume the unit root null is true and fit autoregressive (AR) models to the first differences of the data, using the Schwarz criterion to choose the optimal AR model. Treating the estimated AR coefficients as the true parameters, we then use the optimal AR models in order to generate errors for our data. To determine the finite-sample distributions of our test statistics under the null hypothesis, we use the optimal AR model with iid $\mathrm{N}\left(0, \sigma^{2}\right)$ innovations to construct a pseudo sample of size equal to the actual size of the series, where $\sigma^{2}$ is the estimated innovation variance of the optimal AR model. The test statistic is the t-statistic on $\alpha$ in equations (1), (3) and (6), for unrestricted and restricted models, with the general-to-specific recursive

\footnotetext{
${ }^{9}$ While we could have estimated model BC, which would account for a change in the slope followed by a change in the slope and the intercept of the trend function, there is no economic motivation for that model.
} 
t-statistic procedure used to choose the number of lags. The critical values for the finite sample distributions are taken from the sorted vector of 5000 replicated statistics.

\subsection{Empirical application}

We apply the tests developed above to long-term macro series for the United States. The data consists of annual observations for 14 series, beginning between 1860 and 1909, and ending in 1970. Nelson and Plosser (1982), using augmented Dickey-Fuller tests, found evidence in favor of the unit root null hypothesis for 13 out of the 14 series (the only exception being the unemployment rate) ${ }^{0}$ Zivot and Andrews (1992), incorporating an endogenous breakpoint and finite-sample critical values, reject the unit root null at a 5\% significance level for only three series out of 13 Nelson-Plosser non-stationary series real GNP, nominal GNP and industrial production. Allowing for two endogenous breaks, Lumsdaine and Papell (1997) re-examine the unit root hypothesis for the Nelson-Plosser data. Using finite-sample critical values, they reject the unit root null in favor of the two-break alternative for 5 series (real GNP, nominal GNP, per-capita real GNP, industrial production and employment) at a 5\% significance level.

We calculate critical values using the methodology described in the section 2.2, for each one of the series and also for a finite sample of 100 observations. The common feature of our bootstrapped critical values is that, as the sample size increases, they become lower and also for the series with comparable sizes, the finite sample distributions generated from different AR models are fairly similar. If we compare the critical values across models, we conclude that the highest critical values (in absolute value) are the ones for the model CC series and the lowest for the model CB series (Table 1, 2 and 3). Since model CB allows only for one change in the intercept and two changes in the slope of the trend function, it is not surprising that the corresponding critical values are the lowest among the restricted models. The critical values for the restricted models are uniformly lower (in absolute value) than the critical values for the unrestricted tests. This is the key to the superior power of the restricted trend unit root tests over the unrestricted trend unit root tests when the restricted model is correct.

Since the unemployment rate was previously found to be stationary we consider the remaining 13 series. An issue which has not received much attention in the literature involves determining which model to select for each series. Perron (1989) and Zivot and Andrews (1992) estimate model A for all variables, except real wages and common stock prices, for which they estimate model C. Lumsdaine and Papell

\footnotetext{
${ }^{10}$ A critique of the augmented Dickey Fuller test is the lack of power against stationary alternatives. We used the more powerful tests developed by Elliott at all. (1996) with MAIC lag selection, proposed by $\mathrm{Ng}$ and Perron (2001), which assures a good size of the test. The results do not show any improvement over conventional unit root tests.
} 
(1997) estimate all models for each variable. We estimate all restricted models AA, CC and CB for each series, and use simulation methods (in the next section) to choose among models. 1

We find strong evidence of restricted trend stationarity with model AA for 3 series: real GNP and per-capita real GNP at the 1\% significance level and employment at the 5\% significance level (Table 1). Next we estimate the restricted $\mathrm{CC}$ model, which in addition to the restricted AA model allows for slope changes (Table 2). We find evidence of restricted trend stationarity for 5 series, nominal GNP, per-capita real GNP, employment, GNP deflator and nominal wages, at the 5\% significance level. For the nominal GNP, GNP deflator and nominal wages, the unit root null can be rejected at a higher significance level with model CC than with model AA. For employment, the rejection is at the same significance level and, for per-capita real GNP, it is at a lower significance level with model CC then with model AA. Model CC therefore adds three additional rejections: nominal GNP, GNP deflator and nominal wages.

We also consider model CB, which restricts the first break on the intercept and the slope (Tb1) and the second one on the slope ( $\mathrm{Tb} 2$ ) to produce a long-run constant trend. The results, reported in Table 3, show that, using model CB, we find evidence of restricted trend stationarity for 3 series, real GNP, nominal GNP and per-capita real GNP at the 1\% significance level. For nominal GNP, the unit root null can be rejected at a higher significance level with model CB than with model CC. For other two series, real GNP and per-capita real GNP, the unit root null can be rejected at the same level of significance with model CB as with model AA, but at a higher significance level than with model CC.

Overall, using the restricted models, we reject the unit root null hypothesis at the $5 \%$ significance level or higher for 6 series: real GNP, nominal GNP, per-capita real GNP, employment, GNP deflator and nominal wages. ${ }^{12}$ Comparing the performance of the restricted and unrestricted tests, we conclude the following: For 4 series - real GNP, nominal GNP, per-capita real GNP and employment - the unit root hypothesis is rejected with both unrestricted and restricted tests. There is only one series, industrial production, for which the null is rejected using unrestricted tests but not restricted tests. Lastly, using restricted tests, we add to the previous rejections two more series: the GNP deflator and nominal wages. Combining our results with those of Lumsdaine and Papell (1997), we provide evidence against the Nelson and Plosser hypothesis that all changes are permanent for 7 of the 13 series. These include the major macroeconomic aggregates. The remaining series, for which we do not have evidence against the unit root hypothesis, are generally prices or financial variables.

\footnotetext{
${ }^{11}$ We also estimated the unrestricted models (AA and CC), as in Lumsdaine and Papell (1997). The only difference is that we use 5000 instead of 500 replications to calculate critical values. The rejections are qualitatively similar to theirs, although the significance levels are slightly weaker. We therefore do not report detailed results for the unrestricted models. In addition we estimated the unrestricted model CB, but did not find additional rejections.
} 


\section{Power of the Unit Root Tests with Unrestricted and Restricted Structural Change}

The central empirical result of the paper is that unit root null can be rejected in favor of restricted trend stationarity for 6 out of 13 Nelson-Plosser series, an increase in the rejection number from unit root tests that allow for one or two structural changes in the trend function. But this does not say anything about the economic significance of the results. In order to determine whether these rejections constitute evidence of trend stationarity, or whether they are equally consistent with either broken trend stationarity and/or transitory fluctuations within an underlying unit root process, we perform three simulation experiments to study the performance of the newly developed tests.

\subsection{Power of unit root tests on data that includes one or two structural changes}

We first evaluate the performance of various unit root tests on data that is broken trend stationary: with one break or two breaks that occur in the same direction. This specification is inconsistent with both unit roots and trend stationarity. We consider the following data generating processes:

$$
\begin{aligned}
& y_{t}=\mu+\beta t+\rho y_{t-1}+\gamma D U_{t}+\varepsilon_{t} \\
& y_{t}=\mu+\beta t+\rho y_{t-1}+\gamma_{1} D U 1_{t}+\gamma_{2} D U 2_{t}+\varepsilon_{t}
\end{aligned}
$$

The power of the unit root tests is investigated by constructing series under the alternative hypothesis of broken trend stationary with allowance for one or two shifts in the intercept, consistent with models A and AA. We perform unit root tests on these constructed series, tabulating how often the unit root null is (correctly) rejected. The data set is generated based on different assumptions: we specify $\rho=$ $0.6,0.7,0.8$ and $\beta=0.007$ which reflects the range of values reported in Tables $1-3$. We account for breaks with magnitude of 0.2 and we set the variance of the residuals to be 0.003 , which covers most of the cases found in our data ${ }^{13}$. The timing of the break is set at the $1 / 2$ of the sample for the case with one break and respectively at the $1 / 3$ and $2 / 3$ of the sample for the case including two breaks. In all of these cases the sample size is $\mathrm{T}=100$ and 1000 replications are used with $e_{t}=i i d N(0,1)$. We use finite sample critical values previously calculated and report results for tests of nominal size $10 \%, 5 \%$ and $1 \%$.

The simulation results for trend stationary data that includes one break in the intercept are reported in Table 4. First, as expected, ADF tests have no power on data that includes one structural change and unit root tests that allow for one break in the intercept (Zivot and Andrews model A) have

\footnotetext{
${ }^{12}$ As in Lumsdaine and Papell (1997), we also reject the unit root null at the $10 \%$ significance level for the money stock.

${ }^{13}$ We set these values based on the average ratio between size of the break and the residual variance from our data.
} 
very good power for any level of persistence. ${ }^{14}$ Next we consider the power of tests that incorporate two structural changes (model AA, model CC and model CB). All models have very good power, except for a high level of persistence (0.8), where models $\mathrm{CC}$ and $\mathrm{CB}$ have only moderate power. Comparing power across models we find that model A has the highest power, followed by model AA. This is not surprising since the data is generated with one break in the intercept and no breaks in the slope.

Table 4 also reports the power of tests that incorporate two restricted structural changes (restricted models AA, CC and CB). The three restricted models all have low power, which is desirable since the alternative hypothesis, trend stationarity with one break in the intercept, is inconsistent with any form of restricted structural change. The lowest power is for restricted model $\mathrm{CB}$, followed by restricted models AA and CC. In addition, as with the unrestricted tests, the power of the restricted tests is negatively correlated with the level of persistence.

We then conduct a simulation experiment where the generated data is trend stationary and

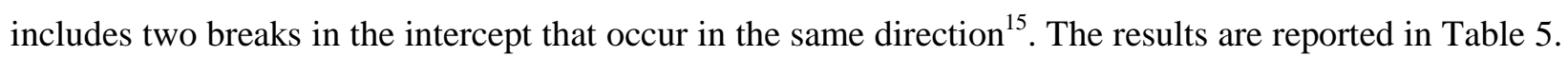
As expected, ADF tests have no power. Unit root tests that allow for one break in the intercept also have no power at any level of persistence. The unrestricted models AA, CC and CB have different power on this type of data: Model AA has very good power for all levels of persistence, model CC has only moderate power, and model CB has no power. The three restricted models, in contrast, have very low power for all levels of persistence. As with the single break alternative, this is a desirable property since trend stationarity with two breaks in the intercept that occur in the same direction is inconsistent with any form of restricted structural change.

The low power of the tests for a unit root in the presence of restricted structural change when the data is broken trend stationary with either one break or two breaks in the same direction allows us to evaluate our results in the light of previous research. Zivot and Andrews (1992) found evidence supporting the Perron hypothesis with one break in the intercept for real GNP, nominal GNP and industrial production. Among these 3 series, we reject the unit root null in favor of the restricted structural change alternative at the $1 \%$ significance level using models AA and CB for real GNP and using model CB for nominal GNP. 16 Since, based on the results in Table 4, these tests have very low power when the data is trend stationary with one break in the intercept, we conclude that it is highly unlikely that real and nominal GNP are broken trend stationary rather than restricted trend stationary. Lumsdaine and Papell (1997) found evidence supporting the Perron hypothesis with two breaks in the intercept for two

\footnotetext{
${ }^{14}$ We consider only model A, which allows for a change in the intercept of the trend function, because Zivot and Andrew estimate model A for all the variables except real wages and common stock prices.

${ }^{15} \mathrm{We}$ do not generate data consistent with models CC and CB because there are too many possibilities for us to feel sanguine in picking a few representative examples.
} 
additional series, per-capita real GNP and employment. We reject the unit root null in favor of the restricted structural change alternative at the $1 \%$ significance level using models AA and CB for percapita real GNP and at the 5\% level using models AA and CC for employment. Since, based on the results in Table 5, these tests have extremely low power when the data is trend stationary with two breaks in the intercept that occur in the same direction, we conclude that it is even more unlikely that per-capita real GNP and employment are broken trend stationary rather than restricted trend stationary.

\section{2. $\quad$ Power of the unit root tests on restricted trend stationary data}

This paper suggests three different tests that impose restrictions in order to assure the alternative of trend stationarity. Using these models, we reject the unit root null in favor of the restricted trend stationarity alternative for 6 out of 13 series. In this section we investigate the possibility of going beyond these results and finding which alternative gives the most of evidence for each series, in accord with the empirical findings. We also examine the power of the restricted tests compared with the unrestricted tests.

We conduct power simulations, restricting to a specific class of data generating processes. The strategy is to estimate models under the hypothesis of interest, for each series, and then study the empirical distribution of the test statistic implied by the fitted model. 17 We consider only series where we rejected the unit root null using a restricted structural change model (real GNP, nominal GNP, per-capita real GNP, employment, GNP deflator and nominal wages), as described in section 2.3.

Within the Monte Carlo experiments we consider the following three data generating processes:

AA restricted model: $y_{t}=\mu+\beta t+\rho y_{t-1}+\gamma_{1} D U 1_{t}+\gamma_{2} D U 2_{t}+\sum_{0}^{k} c_{i} \Delta y_{t-i}+\varepsilon_{t}$, where $\gamma_{1}+\gamma_{2}=0$

CC restricted model: $y_{t}=\mu+\beta t+\rho y_{t-1}+\gamma_{1} D U 1_{t}+\theta_{1} D T 1_{t}+\gamma_{2} D U 2_{t}+\theta_{2} D T 2_{t}+\sum_{0}^{k} c_{i} \Delta y_{t-i}+\varepsilon_{t}$,

where $\theta_{1}+\theta_{2}=0$ and $\gamma_{1}+\gamma_{2}+\theta_{1}\left(T b_{2}-T b_{1}\right)=0$

CB restricted model: $y_{t}=\mu+\beta t+\rho y_{t-1}+\gamma_{1} D U 1_{t}+\theta_{1} D T 1_{t}+\theta_{2} D T 2_{t}+\sum_{0}^{k} c_{i} \Delta y_{t-i}+\varepsilon_{t}$,

where $\theta_{1}+\theta_{2}=0$ and $\gamma+\theta_{1}\left(T b_{2}-T b_{1}\right)=0$

The power of the unit root tests can be investigated by constructing experiments with artificial data, for each model, under an alternative hypothesis where each series is trend stationary with restricted structural change. For each one of the data generating processes we specify different coefficients, based on the previous estimations: for equation (8) we specify the coefficients obtained by estimating real GNP,

\footnotetext{
${ }^{16}$ Since we do not reject the unit root null in favor of the restricted structural change alternative for industrial production, we conclude that it is broken trend stationary.
} 
per-capita real GNP and employment with the restricted model AA (table 6), for equation (9) those obtained by estimating nominal GNP, per-capita real GNP, GNP deflator and nominal wage with the restricted model CC (table 7) and for equation (10) those obtained by estimating real GNP, nominal GNP and per-capita real GNP using restricted model CB (table 8). We then perform unit root tests on these constructed series, tabulating how often the unit root null is (correctly) rejected. The sample size is equal to each series size and 1000 replications are used with $e_{t}=i i d N(0,1)$. We use the bootstrapped critical values previously calculated and report results for tests of nominal size of $10 \%, 5 \%$ and $1 \%$.

We compare the power of the tests across models and series where we reject the unit root null in favor of restricted trend stationarity. In all cases, the ADF tests have no power with these data generating processes. This is consistent with the failure, in Nelson and Plosser (1982), to reject the unit root null for any of these series. For the GNP deflator and the nominal wage the choice is clear: the unit root null is only rejected with the $\mathrm{CC}$ restricted test. As shown in Table 7, the $\mathrm{CC}$ restricted test has good power when the data is generated from a restricted CC model. The other tests, including those with the unrestricted, have little power. This is in accord with the failure, in both Zivot and Andrews (1992) and Lumsdaine and Papell (1997), to reject the unit root null for either of these series.

If the data is generated from a specific estimating process and if that process is correct, the power should be the highest if the test matches the data generating process. We find two cases when where this statement does not apply. First, in the case of nominal GNP the unit root null is rejected using both restricted models CC (5\% significance level) and CB (1\% significance level). In order to make a choice between these two models, we will first verify the power of the two tests, CC and CB restricted, when data is generated from a CC and CB restricted model. We show that regardless of the nature of the data generating process, the $\mathrm{CB}$ tests have the highest power, which suggests that the best representation of nominal GNP is a CB restricted model. As a further check we compare p-values from both models. We find the smallest $\mathrm{p}$-value corresponds to $\mathrm{CB}$ restricted model (0.009) compared with 0.047 corresponding to $\mathrm{CC}$ restricted model. Finally, with the $\mathrm{CC}$ restricted model, the value of the second intercept break is only 0.001 , indicating that the $\mathrm{CB}$ restricted model is preferable.

A similar case is the employment series, where we reject the unit root null using restricted models $\mathrm{AA}$ and $\mathrm{CC}$ at the 5\% significance level. In both cases, if the data is generated as an AA or CC restricted model, the AA restricted tests have the highest power, which suggests that the best representation of employment is an AA restricted model. The p-values comparison, as previously, reinforces our conclusion. In addition, the value of the slope "breaks" with the $\mathrm{CC}$ restricted model are 0.000 , suggesting

\footnotetext{
${ }^{17}$ This parametric bootstrap approach is suggested by Rudebusch (1993).
} 
that the AA restricted model is preferable. The data and breaks for the series for which the unit root null can be rejected in favor of a specific model are illustrated in Figure 1.

Next we find two series where we cannot make a clear choice when choosing a model: real GNP and per-capita real GNP, for which we rejected the unit root null using both restricted models AA and CB at the $1 \%$ significance level. ${ }^{18}$ When the data is generated from an AA restricted model, the AA restricted test will have the highest power but the $\mathrm{CB}$ and $\mathrm{CC}$ restricted tests will also have good power. On the other hand, when the data is generated from a CB restricted model, the CB restricted test will have the highest power but the AA and $\mathrm{CC}$ restricted tests will also have good power. In addition, the p-values from the restricted models $\mathrm{AA}$ and $\mathrm{CB}$ are very similar. We are not able to make a distinction between models AA and CC for real GNP and per-capita real GNP. This is shown in Figure 2.

We argued above that, if a series is broken trend stationary, it would be highly unlikely that the unit root null would be rejected against a restricted structural change alternative. The converse is not true. While, when a series is generated by a particular restricted structural change process, the restricted tests (for that particular model) always have the highest power, the unrestricted tests (for the same model) often also have good power. Thus the rejections, by Lumsdaine and Papell (1997), of the unit root null in favor of broken trend stationarity for real GNP, nominal GNP, per-capita real GNP and employment do not constitute evidence against the restricted structural change hypothesis because, in all cases, the power of model AA is very good when the data is generated by a restricted process.

Using model A with a single break in the intercept, Zivot and Andrews (1992) reject the unit root null in favor of broken trend stationarity (at the 5\% level) for real GNP and nominal GNP. We reject the unit root null in favor of restricted trend stationarity (at the $1 \%$ level) with models AA and CB for real GNP and model CB for nominal GNP. As shown in Tables 6 and 8, the power of the test with Model A when the data is generated by our restricted models is 22.8 (Model AA) and 32.5 (Model CB) for real GNP and 56.4 (Model CB) for nominal GNP (all at the $5 \%$ level). 9 If the true data generating process is consistent with restricted structural change, it would not be too surprising to find a rejection of the unit root null with Model A for either real GNP or nominal GNP (although the results are stronger for nominal GNP than for real GNP).

\footnotetext{
${ }^{18}$ In the case of per-capita real GNP, we also reject the unit root null using the CC restricted model, but only at the $5 \%$ significance level.

${ }^{19}$ In order to be consistent, we calculate finite sample and series specific critical values for the unit root tests that allow one structural change in the intercept (Model A).
} 


\section{3. Restricted unit root tests and transitory fluctuations}

In stark contrast to the Perron hypothesis, several studies have argued that, while real GNP contains a unit root, events surrounding Great Depression and World War II had large but transitory effects. Murray and Nelson (2000) and Kilian and Ohanian (2002) explore the sensitivity of unit root tests to a variety of departures from conventional assumptions. They find that when a temporary component is added to the level of a unit root process, in the form of a one period outlier or a short-lived AR, rejections of the unit root hypothesis occur with high probability and structural breaks are indicated when none occur.

We conduct a simulation experiment in order to investigate the robustness of our tests to these alternatives. We consider the 6 series where we reject the unit root null using restricted structural change tests. Following Murray and Nelson (2002), for each of these series we estimate a simple reduced-form model that captures the view that there were large transitory fluctuations during Great Depression and World War II. This model generates a time series as a sum of a latent random walk with drift and occasional large transitory movements, driven by a regime switching process.

The model is the following:

$y_{t}=\tau_{t}+S_{t} z_{t}$ where $S_{\mathrm{t}}=1$ from 1930-1945

$\tau_{t}=g+\tau_{t-1}+v_{t}$

$z_{t}=\varphi_{1} z_{t-1}+\varphi_{2} z_{t-2}+u_{t}$

where

$$
\left(\begin{array}{l}
v_{t} \\
u_{t}
\end{array}\right) \approx N\left(\left[\begin{array}{l}
0 \\
0
\end{array}\right],\left[\begin{array}{cc}
\sigma^{2}{ }_{v} 0 \\
0 & \sigma^{2}{ }_{u}
\end{array}\right]\right)
$$

The observed time series $\left(y_{t}\right)$ consists of a trend component $\left(\tau_{t}\right)$ and a second component $\left(z_{t}\right)$ which will be present only if an indicator variable $\left(S_{t}\right)$, governed by a Markov process, is unity ${ }^{2} 0$ This second component, if present, adds to the volatility of output and may also have a different dynamics, so we allow it to have an AR (2) structure. Estimation is done by the approximate maximum likelihood method of Kim (1994). Parameters estimates for each series are reported in Table 7.

This model is used as the data generating process in our bootstrap experiments. We perform tests for a unit root in the presence of restricted structural change on these constructed series. For all the series

\footnotetext{
${ }^{20}$ Therefore we treat the Great Depression and World War II as random events that occur with positive probability along the sample path, after 1929 and before 1946.
} 
under consideration, the sample value of the restricted structural change tests is denoted as $\hat{\tau}_{\text {samp }}$. However, the critical values that we previously provided are not valid when the data generated process is a random walk with drift and occasional large transitory movements, driven by a regime switching process. These factors can be taken in account by examining simulated data from the model, for each series, and calculating the exact probability of obtaining the sample value of the test statistic from this particular null model. The test-statistic (denoted by $\hat{\tau}$ ) probability distributions of our restricted tests conditional on the previous model are exhibited in Table 9. Each distribution is formed from 1000 realizations of the tests statistic calculated from 1000 simulated data samples generated from the particular model.

We first focus on the performance of the restricted model AA by testing the models where the parameters are estimated from the real GNP, per-capita real GNP and employment series. The marginal significance level for rejection of the null hypothesis for the model (probability $\left(\hat{\tau}<\hat{\tau}_{\text {samp }}\right)$ ) ranges between 0.042 and 0.066 , which demonstrates that it is highly unlikely that these tests would incorrectly reject the null. Previously, Murray and Nelson (2002) studied the rejection frequencies of an ADF test on the previous model, but using the parameter estimates for long-run US real GDP (1870-1994). They found a marginal significance level for rejection of the null hypothesis of 0.108 . Using restricted model AA, we find strong evidence against the Murray and Nelson hypothesis for these three series, which includes the one series, real GNP, studied by Murray and Nelson (2002). 21

Using the $\mathrm{CC}$ and $\mathrm{CB}$ restricted models to estimate the same three series, the rejection frequencies are higher than in the case of the AA restricted model (between 0.149 and 0.176). It is well known that unit root tests have difficulties in distinguishing trending data from a random walk with drift. Therefore it is not surprising that unit root tests that allow for changes in slopes of the trend function behave somewhat worse than tests that allow for only changes in the intercept. As we allow for more changes in the trend function when testing for a unit root, it will be harder to differentiate between the two alternatives, unit root and trend-stationarity. Therefore, in all cases, not only does the AA restricted model perform better than the $\mathrm{CC}$ and $\mathrm{CB}$ restricted models but the $\mathrm{CB}$ restricted model performs better than $\mathrm{CC}$ restricted model.

Cochrane (1991) demonstrated that we cannot distinguish between the case in which the nonstationary component of a series has a small innovation variance and the case of a stationary series. Engel (2000) decomposes real exchange rates into a stationary and a non-stationary component, and shows that the size of unit root tests becomes larger as the ratio between the non-stationary and stationary component

\footnotetext{
${ }^{21}$ Papell and Prodan (2004) report a similar result for long-run US real GDP (1870-1998). See Murray and Nelson (2004) for a rejoinder.
} 
becomes smaller. Our results show that as this ratio becomes smaller, the frequency of rejections becomes larger, using any of the restricted models. This issue becomes distinct when estimating models for series as GNP deflator, nominal wage and nominal GNP, where the ratio between the non-stationary and stationary component becomes smaller than the previous cases (real GNP, per-capita real GNP and employment series). Compared with previous results, the CB and (especially) the CC restricted models perform worse then the AA restricted models (the frequency of the rejections ranges between 0.303 and $0.755)$.

\section{Conclusions}

Do aggregate macroeconomic and financial time series have a unit root? Despite the large volume of research that has been done on this topic, there is not yet a definitive conclusion. The debate started with Nelson and Plosser (1982). In contrast to the traditional view, they found evidence for the unit root hypothesis for 13 out 14 long-term annual macro series. Later studies questioned these results, the argument being either the low power of unit root tests or the failure to account for permanent structural change when testing for unit roots. On the other hand, studies have also pointed out weaknesses of unit root tests that allow for structural change, raising the question about whether the data can be viewed as a random walk with drift characterized by occasional large transitory fluctuations.

In this paper we propose a new hypothesis: restricted structural change. We allow for two offsetting structural changes which restrict the underlying process to trend stationarity and develop three versions of the tests, incorporating restrictions on shifts in the intercept and shifts in the slope. We reject the unit root null in favor of restricted trend stationarity for 6 out of 13 macroeconomic series at the 5\% significance level: real GNP, nominal GNP, per-capita real GNP, employment, GNP deflator and nominal wage. On the other hand, we do not find evidence of restricted trend stationarity for prices or financial series. Combined with the Lumsdaine and Papell (1997) rejections of the unit root null in favor of a broken trend stationary alternative, our rejections provide strong evidence against the Nelson and Plosser hypothesis that all changes are permanent for the macroeconomic aggregates.

The simulation experiments reinforce our empirical results. There are three conclusions that we can draw: First, we find evidence that the restricted tests have low power when the data is generated as trend stationarity with one break or two breaks in the same direction. Our rejections therefore provide evidence against the Perron hypothesis that the series are stationary except for one or two permanent structural changes associated with the Great Depression and the two World Wars for real GNP, nominal GNP, per-capita real GNP and employment. Second, performing power simulations on a specific class of data generating process, we show that the Lumsdaine and Papell (1997) rejections in favor of broken trend stationarity do not provide evidence against the restricted structural change hypothesis. Taking into 
account our previous empirical findings, we also provide some evidence to choose among the various restricted structural change models. Finally, we show that, even if the data is generated as a random walk with drift characterized by large transitory fluctuations, the AA restricted tests are not biased toward rejections. This provides strong evidence against the Murray and Nelson hypothesis that one change, The Great Depression, is transitory and all others are permanent for three of the series: real GNP; per-capita real GNP, and employment. Taking in account these results, we conclude that our tests provide strong evidence of trend stationarity in the presence of restricted structural change for the six series where we reject the unit root null. 


\section{References}

Barro, Robert (1981), “Output Effects of Government Purchases,” Journal of Political Economy, 89, 1086-1121.

Blanchard, Olivier J. (1981), "What is Left of the Multiplier Accelerator?" American Economic Review, $71,150-1534$.

Beaudry, Paul and Gary Koop (1993), “Do Recessions Permanently Change Output?” Journal of Monetary Economics, 31, 149-163.

Banerjee, Anindya; Robin Lumsdaine and James H. Stock (1992), "Recursive and Sequential Tests of the Unit Root and Trend-Break Hypotheses: Theory and International Evidence," Journal of Business and Economic Statistics, 10, 271-287.

Campbell, John Y. and Gregory N. Mankiw (1987), “Are Output Fluctuations Transitory?” Quarterly Journal of Economics, 102, 857-880.

Dickey, David A. and Wayne A. Fuller (1979), "Distribution of the Estimators for Autoregressive Time Series with a Unit Root," Journal of American Statistical Association, 74, 427-431.

Christiano, Lawrence J. (1992), "Searching for a Break in GNP," Journal of Business and Economic Statistics, 10, 237-250.

Cochrane, John H. (1988), "How Big is the Random Walk in GNP?" Journal of Political Economy, 96, 893-920.

Cochrane, John H. (1991), “A Critique of the Application of the Unit Root Tests," Journal of Economic Dynamics and Control, 12, 447-461.

Elliott, Graham; Thomas J. Rothenberg and James H. Stock (1996), "Efficient Tests for an Autoregressive Unit Root," Econometrica, 64, 813-836.

Engel, Charles (2000), “Long Run PPP May not Hold After All,” Journal of International Economics, 57, 243-273.

Friedman, Milton and Anna J. Schwartz (1963), “A Monetary History of the United States, 1867-1960," Princeton, NJ: Princeton University Press.

Gould, John P. and Charles R. Nelson (1974), “The Stochastic Structure of the Velocity of Money," American Economic Review, June, 405-18.

Kilian, Lutz and Lee Ohanian (2002), "Unit Roots, Trend Breaks, and Transitory Dynamics: A Macroeconomic Perspective," Macroeconomic Dynamics, 6, 614-631. 
Kim, Chang-Jin and Charles Nelson (1999), “Friedman's Plucking Model of Business Fluctuations and Estimates of Permanent and Transitory Components," Journal of Money, Credit and Banking, 318-334.

Kydland, Finn and Edward C. Prescott (1989), “A Competitive Theory of Fluctuations and the Feasibility and Desirability of Stabilization Policy," in Rational Expectations and Economic Policy, Stanley Ficher (ed.), Chicago: University of Chicago Press, 169-189.

Lumsdaine, Robin L. and David H. Papell (1997), "Multiple Trend Breaks and the Unit Root Hypothesis," The Review of Economics and Statistics, May 1997, 212-218.

Murray, Christian and Charles R. Nelson (2000), "The Uncertain Trend in U.S. GDP," Journal of Monetary Economics, 46, 79-95.

Murray, Christian and Charles R. Nelson (2002), “The Great Depression and Output Persistence," Journal of Money, Credit and Banking, 34, 1090-1098.

Murray, Christian and Charles R. Nelson (2004), "The Great Depression and Output Persistence: A Reply to Papell and Prodan” Journal of Money, Credit and Banking, 36, 429-432.

Nelson, Charles R. and Charles I. Plosser (1982), "Trends and Random Walks in Macro-Economic Time Series: Some Evidence and Implications," Journal of Monetary Economics, 10, 139-162.

Ng, Serena and Pierre Perron (1995), "Unit Root Test in ARMA Models with Data dependent Methods for the Selection of the Truncation Lag" Journal of the American Statistical Association, 90, 268-281.

Ng, Serena and Pierre Perron (2001), "Lag Length Selection and the Construction of Unit Root Tests with Good Size and Power," Econometrica, 69, 1519-1554.

Papell, David H. and Ruxandra Prodan (2004), “The Uncertain Unit Root in U.S. Real GDP: Evidence with Restricted and Unrestricted Structural Change," Journal of Money, Credit and Banking, 36, 423-427. Papell, David H. and Ruxandra Prodan (2005), "Long Run Purchasing Power Parity: Cassel or BalassaSamuelson?" working paper, University of Houston.

Perron, Pierre (1989), "The Great Crash, the Oil Price Shock, and the Unit Root Hypothesis," Econometrica, 57, 1361-1401.

Perron, Pierre (1994), "Trend, Unit Root and Structural Change in Macroeconomic Time Series," in Cointegration for the Applied Economist, B.B. Rao (ed.), Basingstoke: Macmillan Press, 113-146.

Rudebusch, Glenn D. (1992), "Trends and Random Walks in Macroeconomic Time Series: A ReExamination," International Economic Review, 33, 661-680. 
Rudebusch, Glenn D. (1993), "The Uncertain Unit Root in Real GNP," The American Economic Review, $83,264-272$.

Samuelson, Paul (1973), 'Proof That Properly Discounted Present Values of Assets Vibrate Randomly,'

The Bell Journal of Economics and Management Science, 4, 369-374.

Zivot, Eric and Donald Andrews (1992), "Further Evidence on the Great Crash, the Oil Price Shock and the Unit Root Hypothesis,” Journal of Business and Economic Statistics, 3, 251-270. 
Table 1. Restricted tests - Model AA

$\Delta y_{t}=\mu+\beta t+\gamma_{1} D U 1_{t}+\gamma_{2} D U 2_{t}+\alpha y_{t-1}+\sum_{i=1}^{k} c_{i} \Delta y_{t-i}+\varepsilon_{t}, \quad$ s.t. $\quad \gamma_{1}+\gamma_{2}=0$

\begin{tabular}{l|c|l|r|r|r|r|r|r}
\hline \multicolumn{1}{c|}{ Series } & $\alpha$ & t-stat & p-val & TB1 & $\gamma_{1}$ & TB2 & $\gamma_{2}$ & $\mathrm{k}$ \\
\hline \hline Real GNP & -0.49 & $-6.67 * * *$ & 0.01 & 1929 & -0.140 & 1939 & 0.140 & 2 \\
Nominal GNP & -0.49 & $-5.90 *$ & 0.06 & 1929 & -0.200 & 1949 & 0.200 & 7 \\
Per-capita real GNP & -0.53 & $-6.72 * * *$ & 0.01 & 1929 & -0.140 & 1939 & 0.140 & 2 \\
Ind. Production & -0.58 & -5.13 & 0.18 & 1869 & 0.230 & 1929 & -0.230 & 8 \\
Employment & -0.61 & $-6.27 * *$ & 0.02 & 1908 & 0.060 & 1929 & -0.060 & 8 \\
GNP deflator & -0.19 & -4.41 & 0.61 & 1929 & -0.060 & 1945 & 0.060 & 1 \\
Consumer Prices & -0.07 & -3.55 & 0.94 & 1882 & -0.030 & 1940 & 0.030 & 5 \\
Nominal wages & -0.31 & -5.62 & 0.12 & 1908 & 0.140 & 1929 & -0.140 & 7 \\
Real wages & -0.36 & -5.15 & 0.22 & 1929 & -0.060 & 1940 & 0.060 & 1 \\
Money stock & -0.36 & $-5.68 *$ & 0.09 & 1915 & 0.080 & 1930 & -0.080 & 8 \\
Velocity & -0.28 & -4.78 & 0.31 & 1884 & -0.100 & 1949 & 0.100 & 1 \\
Interest rate & -0.20 & -3.95 & 0.79 & 1932 & -0.150 & 1965 & 0.150 & 5 \\
Common stock prices & -0.23 & -4.89 & 0.31 & 1929 & -0.200 & 1953 & 0.200 & 1 \\
\hline \hline
\end{tabular}

Note: The critical values are calculated for each series using finite sample distributions.

$* * *$ Significant at $1 \%$ level

** Significant at 5\% level

* $\quad$ Significant at $10 \%$ level

\begin{tabular}{l|c||ccc}
\hline \hline \multicolumn{1}{c|}{ Series } & & \multicolumn{3}{c}{ Finite-sample critical values } \\
\cline { 2 - 5 } & $\mathbf{T}$ & $\mathbf{9 9 \%}$ & $\mathbf{9 5 \%}$ & $\mathbf{9 0 \%}$ \\
Finite-sample & 100 & -6.29 & -5.73 & -5.47 \\
Real GNP & 62 & -6.53 & -5.93 & -5.63 \\
Nominal GNP & 62 & -6.82 & -6.04 & -5.66 \\
Per-capita real GNP & 62 & -6.43 & -5.88 & -5.57 \\
Ind. Production & 111 & -6.23 & -5.65 & -5.39 \\
Employment & 81 & -6.45 & -5.83 & -5.54 \\
GNP deflator & 82 & -6.47 & -5.86 & -5.56 \\
Consumer Prices & 111 & -6.30 & -5.74 & -5.47 \\
Nominal wages & 71 & -6.59 & -5.98 & -5.68 \\
Real wages & 71 & -6.51 & -5.87 & -5.56 \\
Money stock & 82 & -6.50 & -5.93 & -5.62 \\
Velocity & 102 & -6.20 & -5.67 & -5.37 \\
Interest rate & 71 & -6.43 & -5.86 & -5.55 \\
Common stock prices & 100 & -6.28 & -5.78 & -5.47 \\
\hline \hline
\end{tabular}


Table 2. Restricted tests - Model CC

$\Delta y_{t}=\mu+\beta t+\gamma_{1} D U 1_{t}+\theta_{1} D T 1_{t}+\gamma_{2} D U 2_{t}+\theta_{2} D T 2_{t}+\alpha y_{t-1}+\sum_{i=1}^{k} c_{i} \Delta y_{t-i}+\varepsilon_{t}$
s.t. $\theta_{1}+\theta_{2}=0$ and $\gamma_{1}+\gamma_{2}+\theta_{1}\left(T b_{2}-T b_{1}\right)=0$,

\begin{tabular}{l|c|c|r|r|r|r|r|r|r|r}
\hline \multicolumn{1}{c|}{ Series } & $\alpha$ & t-stat & p-val & TB1 & $\gamma_{1}$ & $\theta_{1}$ & TB2 & $\gamma_{2}$ & $\theta_{2}$ & $\mathrm{k}$ \\
\hline \hline Real GNP & -0.40 & $-6.01^{*}$ & 0.08 & 1929 & -0.140 & 0.002 & 1938 & 0.120 & -0.002 & 1 \\
Nominal GNP & -0.49 & $-6.25^{* *}$ & 0.05 & 1929 & -0.310 & 0.009 & 1963 & 0.001 & -0.009 & 8 \\
Per-capita real GNP & -0.83 & $-6.35^{* *}$ & 0.04 & 1929 & -0.220 & 0.010 & 1955 & -0.049 & -0.010 & 8 \\
Ind. Production & -0.61 & -5.12 & 0.33 & 1878 & 0.120 & 0.001 & 1929 & -0.182 & -0.001 & 8 \\
Employment & -0.61 & $-6.21^{* *}$ & 0.05 & 1908 & 0.060 & 0.000 & 1929 & -0.064 & -0.000 & 8 \\
GNP deflator & -0.25 & $-6.64 * *$ & 0.02 & 1915 & 0.120 & -0.010 & 1940 & 0.125 & 0.010 & 1 \\
Consumer Prices & -0.08 & -3.50 & 0.10 & 1882 & -0.040 & 0.000 & 1945 & 0.029 & -0.000 & 5 \\
Nominal wages & -0.32 & $-6.33^{* *}$ & 0.04 & 1917 & 0.160 & -0.015 & 1940 & 0.188 & 0.015 & 1 \\
Real wages & -0.41 & -5.35 & 0.24 & 1909 & -0.010 & -0.002 & 1940 & 0.076 & 0.002 & 1 \\
Money stock & -0.31 & -5.34 & 0.21 & 1915 & 0.090 & -0.002 & 1930 & -0.059 & 0.002 & 8 \\
Velocity & -0.29 & -4.85 & 0.48 & 1884 & -0.090 & -0.000 & 1949 & 0.118 & 0.000 & 1 \\
Interest rate & -0.16 & -3.77 & 0.91 & 1932 & -0.190 & 0.002 & 1967 & 0.109 & -0.002 & 0 \\
Common stock prices & -0.33 & -5.35 & 0.23 & 1886 & -0.060 & -0.004 & 1953 & 0.327 & 0.004 & 1 \\
\hline \hline
\end{tabular}

Note: The critical values are calculated for each series using finite sample distributions.

$* * *$ Significant at $1 \%$ level

** Significant at 5\% level

* Significant at $10 \%$ level

\begin{tabular}{l||l|lll}
\hline \multicolumn{1}{c|}{ Series } & & \multicolumn{3}{c}{ Finite-sample critical values } \\
\cline { 2 - 5 } & T & $\mathbf{9 9 \%}$ & $\mathbf{9 5 \%}$ & $\mathbf{9 0 \%}$ \\
Finite-sample & 100 & -6.71 & -6.15 & -5.86 \\
Real GNP & 62 & -6.77 & -6.22 & -5.91 \\
Nominal GNP & 62 & -7.11 & -6.23 & -5.83 \\
Per-capita real GNP & 62 & -6.78 & -6.23 & -5.89 \\
Ind. Production & 111 & -6.58 & -6.01 & -5.72 \\
Employment & 81 & -6.86 & -6.17 & -5.83 \\
GNP deflator & 82 & -6.83 & -6.20 & -5.88 \\
Consumer Prices & 111 & -6.64 & -6.03 & -5.75 \\
Nominal wages & 71 & -6.87 & -6.21 & -5.96 \\
Real wages & 71 & -6.82 & -6.16 & -5.86 \\
Money stock & 82 & -6.75 & -6.09 & -5.75 \\
Velocity & 102 & -6.61 & -6.07 & -5.76 \\
Interest rate & 71 & -6.85 & -6.23 & -5.88 \\
Common stock prices & 100 & -6.70 & -6.10 & -5.79 \\
\hline \hline
\end{tabular}


Table 3. Restricted tests - Model CB

$\Delta y_{t}=\mu+\beta t+\gamma_{1} D U 1_{t}+\theta_{1} D T 1_{t}+\theta_{2} D T 2_{t}+\alpha y_{t-1}+\sum_{i=1}^{k} c_{i} \Delta y_{t-i}+\varepsilon_{t}$

s.t. $\theta_{1}+\theta_{2}=0$ and $\gamma+\theta_{1}\left(T b_{2}-T b_{1}\right)=0$

\begin{tabular}{r||c|l|c|c|c|c|c|c|c}
\hline \multicolumn{1}{c|}{ Series } & $\alpha$ & t-stat & p-val & TB1 & $\gamma_{1}$ & $\theta_{1}$ & TB2 & $\theta_{2}$ & $\mathrm{k}$ \\
& & & & & & & & & \\
\hline Real GNP & -0.38 & $-6.25^{* * *}$ & 0.01 & 1929 & -0.183 & 0.013 & 1943 & -0.013 & 1 \\
Nominal GNP & -0.39 & $-6.49^{* * *}$ & 0.01 & 1929 & -0.309 & 0.012 & 1955 & -0.012 & 6 \\
Per-capita real GNP & -0.80 & $-6.21^{* * *}$ & 0.01 & 1929 & -0.210 & 0.010 & 1951 & -0.010 & 8 \\
Ind. Production & -0.29 & -4.58 & 0.25 & 1929 & -0.263 & 0.019 & 1943 & -0.019 & 5 \\
Employment & -0.36 & -4.71 & 0.28 & 1908 & 0.050 & -0.002 & 1932 & 0.002 & 7 \\
GNP deflator & -0.17 & -4.33 & 0.39 & 1930 & -0.094 & 0.005 & 1948 & -0.005 & 1 \\
Consumer Prices & -0.06 & -3.02 & 0.90 & 1882 & -0.034 & 0.001 & 1968 & -0.001 & 5 \\
Nominal wages & -0.32 & -4.91 & 0.18 & 1930 & -0.127 & 0.004 & 1959 & -0.004 & 7 \\
Real wages & -0.32 & -4.96 & 0.16 & 1931 & -0.091 & 0.008 & 1942 & -0.008 & 1 \\
Money stock & -0.25 & $-5.29 *$ & 0.07 & 1915 & 0.099 & -0.006 & 1932 & 0.006 & 8 \\
Velocity & -0.12 & -2.98 & 0.91 & 1880 & -0.078 & 0.001 & 1968 & -0.001 & 0 \\
Interest rate & -0.14 & -2.80 & 0.91 & 1934 & -0.165 & 0.005 & 1968 & -0.005 & 0 \\
Common stock prices & -0.20 & -4.60 & 0.25 & 1929 & -0.272 & 0.008 & 1962 & -0.008 & 1 \\
\hline \hline
\end{tabular}

Note: The critical values are calculated for each series using finite sample distributions.

*** Significant at $1 \%$ level

** Significant at $5 \%$ level

* Significant at $10 \%$ level

\begin{tabular}{l|c||ccc}
\hline \hline \multicolumn{1}{c|}{ Series } & & \multicolumn{3}{c}{ Finite-sample critical values } \\
\cline { 2 - 5 } & T & $\mathbf{9 9 \%}$ & $\mathbf{9 5 \%}$ & $\mathbf{9 0 \%}$ \\
Finite-sample & 100 & -5.79 & -5.22 & -4.93 \\
Real GNP & 62 & -6.15 & -5.56 & -5.24 \\
Nominal GNP & 62 & -6.42 & -5.62 & -5.24 \\
Per-capita real GNP & 62 & -6.14 & -5.53 & -5.21 \\
Ind. Production & 111 & -5.98 & -5.33 & -5.06 \\
Employment & 81 & -6.17 & -5.47 & -5.18 \\
GNP deflator & 82 & -6.06 & -5.48 & -5.18 \\
Consumer Prices & 111 & -5.98 & -5.37 & -5.07 \\
Nominal wages & 71 & -6.27 & -5.58 & -5.25 \\
Real wages & 71 & -6.08 & -5.53 & -5.23 \\
Money stock & 82 & -6.19 & -5.50 & -5.15 \\
Velocity & 102 & -5.96 & -5.35 & -5.06 \\
Interest rate & 71 & -6.15 & -5.52 & -5.19 \\
Common stock prices & 100 & -6.10 & -5.44 & -5.11 \\
\hline \hline
\end{tabular}


Table 4. Power of unit root tests on data generated with one break in the intercept (model A)

\begin{tabular}{|c|c|c|c|c|c|c|}
\hline \hline \multirow{2}{*}{$\rho$} & \multicolumn{3}{|c|}{ ADF TEST } & \multicolumn{3}{c|}{ Model A } \\
\cline { 2 - 7 } & $1 \%$ & $5 \%$ & $10 \%$ & $1 \%$ & $5 \%$ & $10 \%$ \\
\hline $\mathbf{0 . 6}$ & 0.00 & 0.00 & 0.00 & 0.87 & 0.98 & 0.99 \\
\hline $\mathbf{0 . 7}$ & 0.00 & 0.00 & 0.00 & 0.80 & 0.96 & 0.99 \\
\hline $\mathbf{0 . 8}$ & 0.00 & 0.00 & 0.00 & 0.74 & 0.94 & 0.97 \\
\hline \hline
\end{tabular}

\begin{tabular}{|l|c|c|c|c|c|c|c|c|c|c|c|c|c|c|c|c|c|c|}
\hline \hline \multirow{2}{*}{$\boldsymbol{\rho}$} & \multicolumn{3}{|c|}{ Model AA } & \multicolumn{3}{|c|}{$\begin{array}{c}\text { Model AA } \\
\text { RESTRICTED }\end{array}$} & \multicolumn{3}{c|}{ Model CC } & \multicolumn{3}{c|}{$\begin{array}{c}\text { Model CC } \\
\text { RESTRICTED }\end{array}$} & \multicolumn{3}{c|}{ Model CB } & \multicolumn{2}{c|}{ Model CB } \\
RESTRICTED
\end{tabular}

Note: Data generating process: $y_{t}=\mu+\beta t+\rho y_{t-1}+\gamma D U_{t}+\varepsilon_{t}$. Specifications: $\rho=0.6,0.7,0.8, \beta=0.007, \gamma=0.2$ and $\sigma_{\varepsilon}=0.003$. The timing of the break is set at $1 / 2$ of the sample. 
Table 5. Power of the unit root tests on data generated with two breaks in the intercept (model AA)

\begin{tabular}{|c|c|c|c|c|c|c|}
\hline \hline \multirow{2}{*}{$\boldsymbol{\rho}$} & \multicolumn{3}{|c|}{ ADF TEST } & \multicolumn{3}{c|}{ Model A } \\
\cline { 2 - 7 } & $1 \%$ & $5 \%$ & $10 \%$ & $1 \%$ & $5 \%$ & $10 \%$ \\
\hline $\mathbf{0 . 6}$ & 0.00 & 0.03 & 0.13 & 0.00 & 0.00 & 0.01 \\
\hline $\mathbf{0 . 7}$ & 0.00 & 0.00 & 0.05 & 0.00 & 0.00 & 0.01 \\
\hline $\mathbf{0 . 8}$ & 0.00 & 0.00 & 0.00 & 0.00 & 0.00 & 0.02 \\
\hline \hline
\end{tabular}

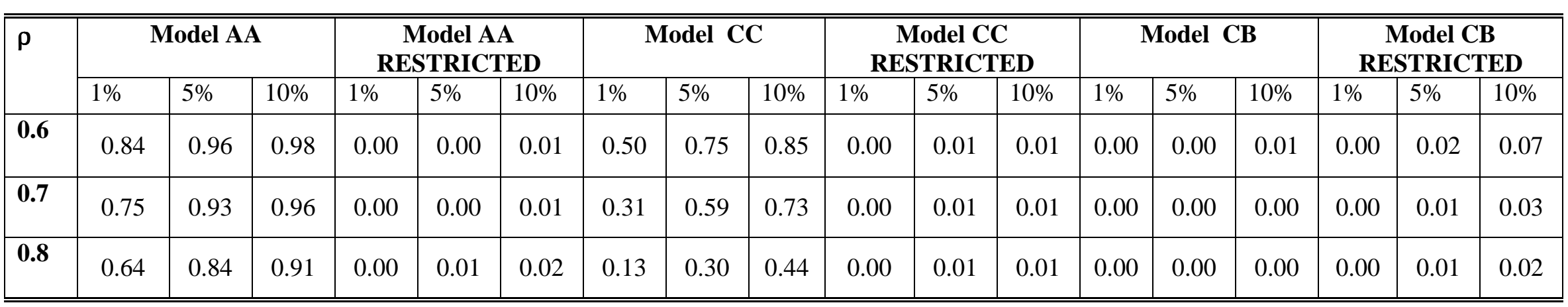

Note: Data generating process: $y_{t}=\mu+\beta t+\rho y_{t-1}+\gamma_{1} D U 1_{t}+\gamma_{2} D U 2_{t}+\varepsilon_{t}$. Specifications: $\rho=0.6,0.7,0.8, \beta=0.007, \gamma_{\mathrm{i}}=0.2$ and $\sigma_{\varepsilon}=0.003$. The timing of the breaks is set at $1 / 3$ and $2 / 3$ of the sample. 
Table 6. Power of the unit root tests on generated data with AA restricted model

\begin{tabular}{|c|c|c|c|c|}
\hline & & RGNP & PCRGNP & EMPLOYMENT \\
\hline \multirow[t]{3}{*}{ ADF } & $1 \%$ & 0.00 & 0.00 & 0.00 \\
\hline & $5 \%$ & 0.00 & 0.00 & 0.00 \\
\hline & $10 \%$ & 0.00 & 0.00 & 0.06 \\
\hline \multirow[t]{3}{*}{ Model A } & $1 \%$ & 0.06 & 0.06 & 0.12 \\
\hline & $5 \%$ & 0.23 & 0.21 & 0.34 \\
\hline & $10 \%$ & 0.36 & 0.37 & 0.54 \\
\hline \multirow[t]{3}{*}{ Model AA } & $1 \%$ & 0.36 & 0.46 & 0.67 \\
\hline & $5 \%$ & 0.68 & 0.74 & 0.90 \\
\hline & $10 \%$ & 0.81 & 0.86 & 0.95 \\
\hline \multirow{3}{*}{$\begin{array}{l}\text { Model AA } \\
\text { RESTRICTED }\end{array}$} & $1 \%$ & 0.59 & 0.63 & 0.79 \\
\hline & $5 \%$ & 0.86 & 0.88 & 0.93 \\
\hline & $10 \%$ & 0.93 & 0.94 & 0.98 \\
\hline \multirow[t]{3}{*}{ Model CC } & $1 \%$ & 0.07 & 0.08 & 0.38 \\
\hline & $5 \%$ & 0.20 & 0.26 & 0.68 \\
\hline & $10 \%$ & 0.36 & 0.43 & 0.82 \\
\hline \multirow{3}{*}{$\begin{array}{l}\text { Model CC } \\
\text { RESTRICTED }\end{array}$} & $1 \%$ & 0.35 & 0.42 & 0.68 \\
\hline & $5 \%$ & 0.67 & 0.74 & 0.90 \\
\hline & $10 \%$ & 0.86 & 0.90 & 0.94 \\
\hline \multirow[t]{3}{*}{ Model CB } & $1 \%$ & 0.02 & 0.02 & 0.13 \\
\hline & $5 \%$ & 0.07 & 0.10 & 0.39 \\
\hline & $10 \%$ & 0.47 & 0.19 & 0.58 \\
\hline \multirow{3}{*}{$\begin{array}{l}\text { Model CB } \\
\text { RESTRICTED }\end{array}$} & $1 \%$ & 0.32 & 0.37 & 0.39 \\
\hline & $5 \%$ & 0.66 & 0.74 & 0.74 \\
\hline & $10 \%$ & 0.82 & 0.87 & 0.87 \\
\hline
\end{tabular}

Note: The series are generated under an alternative hypothesis where each series is trend stationary with restricted structural change (model AA restricted):

$y_{t}=\mu+\beta t+\rho y_{t-1}+\gamma_{1} D U 1_{t}+\gamma_{2} D U 2_{t}+\sum_{0}^{k} c_{i} \Delta y_{t-i}+\varepsilon_{t}$

For each of the data generating processes the coefficients are based on the previous estimations. Unit root tests are performed on these constructed series, tabulating how often the unit root null is (correctly) rejected. We use the bootstrapped critical values previously calculated and report results for tests of nominal size of $10 \%, 5 \%$ and $1 \%$. 
Table 7. Power of the unit root tests on generated data with $\mathrm{CC}$ restricted model

\begin{tabular}{|c|c|c|c|c|c|c|}
\hline & & NGNP & PCRGNP & EMPLOYMENT & GNP deflator & N. WAGE \\
\hline \multirow[t]{3}{*}{$\overline{\mathrm{ADF}}$} & $1 \%$ & 0.00 & 0.00 & 0.00 & $\begin{array}{l}0.00 \\
\end{array}$ & 0.00 \\
\hline & $5 \%$ & 0.00 & 0.00 & 0.01 & 0.01 & 0.00 \\
\hline & $10 \%$ & 0.00 & 0.00 & 0.04 & 0.05 & 0.02 \\
\hline \multirow[t]{3}{*}{ Model A } & $1 \%$ & 0.57 & 0.19 & 0.12 & 0.07 & 0.02 \\
\hline & $5 \%$ & 0.84 & 0.42 & 0.34 & 0.06 & 0.02 \\
\hline & $10 \%$ & 0.92 & 0.61 & 0.54 & 0.14 & 0.06 \\
\hline \multirow[t]{3}{*}{ Model AA } & $1 \%$ & 0.69 & 0.65 & 0.69 & 0.00 & 0.00 \\
\hline & $5 \%$ & 0.95 & 0.88 & 0.90 & 0.02 & 0.01 \\
\hline & $10 \%$ & 0.98 & 0.95 & 0.95 & 0.07 & 0.03 \\
\hline \multirow{3}{*}{$\begin{array}{l}\text { Model AA } \\
\text { RESTRICTED }\end{array}$} & $1 \%$ & 0.06 & 0.52 & 0.76 & 0.00 & 0.00 \\
\hline & $5 \%$ & 0.31 & 0.78 & 0.93 & 0.01 & 0.01 \\
\hline & $10 \%$ & 0.54 & 0.91 & 0.97 & 0.02 & 0.03 \\
\hline \multirow[t]{3}{*}{ Model CC } & $1 \%$ & 0.47 & 0.76 & 0.40 & 0.07 & 0.07 \\
\hline & $5 \%$ & 0.78 & 0.91 & 0.69 & 0.24 & 0.24 \\
\hline & $10 \%$ & 0.89 & 0.95 & 0.81 & 0.36 & 0.38 \\
\hline \multirow{3}{*}{$\begin{array}{l}\text { Model CC } \\
\text { RESTRICTED }\end{array}$} & $1 \%$ & 0.77 & 0.94 & 0.69 & 0.36 & 0.48 \\
\hline & $5 \%$ & 0.95 & 0.99 & 0.90 & 0.64 & 0.76 \\
\hline & $10 \%$ & 0.98 & 0.99 & 0.95 & 0.77 & 0.84 \\
\hline \multirow[t]{3}{*}{ Model CB } & $1 \%$ & 0.24 & 0.76 & 0.13 & 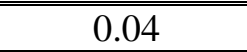 & 0.00 \\
\hline & $5 \%$ & 0.68 & 0.92 & 0.41 & 0.18 & 0.02 \\
\hline & $10 \%$ & 0.85 & 0.96 & 0.60 & 0.28 & 0.04 \\
\hline \multirow{3}{*}{$\begin{array}{l}\text { Model CB } \\
\text { RESTRICTED }\end{array}$} & $1 \%$ & 0.92 & 0.98 & 0.34 & 0.00 & 0.00 \\
\hline & $5 \%$ & 0.99 & 1.00 & 0.69 & 0.04 & 0.01 \\
\hline & $10 \%$ & 1.00 & 1.00 & 0.82 & 0.08 & 0.05 \\
\hline
\end{tabular}

Note: The series are generated under an alternative hypothesis where each series is trend stationary with restricted structural change (model CC restricted):

$y_{t}=\mu+\beta t+\rho y_{t-1}+\gamma_{1} D U 1_{t}+\theta_{1} D T 1_{t}+\gamma_{2} D U 2_{t}+\theta_{2} D T 2_{t}+\sum_{0}^{k} c_{i} \Delta y_{t-i}+\varepsilon_{t}$

For each of the data generating processes the coefficients are based on the previous estimations. Unit root tests are performed on these constructed series, tabulating how often the unit root null is (correctly) rejected. We use the bootstrapped critical values previously calculated and report results for tests of nominal size of $10 \%, 5 \%$ and $1 \%$. 
Table 8. Power of the unit root tests on generated data with CB restricted model

\begin{tabular}{|c|c|c|c|c|}
\hline & & RGNP & NGNP & PCRGNP \\
\hline \multirow[t]{3}{*}{ ADF } & $1 \%$ & 0.00 & 0.00 & 0.00 \\
\hline & $5 \%$ & 0.00 & 0.00 & 0.00 \\
\hline & $10 \%$ & 0.01 & 0.00 & 0.00 \\
\hline \multirow[t]{3}{*}{ Model A } & $1 \%$ & 0.14 & 0.08 & 0.35 \\
\hline & $5 \%$ & 0.33 & 0.08 & 0.61 \\
\hline & $10 \%$ & 0.44 & 0.22 & 0.76 \\
\hline \multirow[t]{3}{*}{ Model AA } & $1 \%$ & 0.41 & 0.47 & 0.76 \\
\hline & $5 \%$ & 0.66 & 0.86 & 0.93 \\
\hline & $10 \%$ & 0.77 & 0.93 & 0.97 \\
\hline \multirow{3}{*}{$\begin{array}{l}\text { Model AA } \\
\text { RESTRICTED }\end{array}$} & $1 \%$ & 0.32 & 0.13 & 0.48 \\
\hline & $5 \%$ & 0.59 & 0.47 & 0.74 \\
\hline & $10 \%$ & 0.73 & 0.70 & 0.87 \\
\hline \multirow[t]{3}{*}{ Model CC } & $1 \%$ & 0.14 & 0.25 & 0.71 \\
\hline & $5 \%$ & 0.35 & 0.58 & 0.89 \\
\hline & $10 \%$ & 0.51 & 0.72 & 0.94 \\
\hline \multirow{3}{*}{$\begin{array}{l}\text { Model CC } \\
\text { RESTRICTED }\end{array}$} & $1 \%$ & 0.41 & 0.56 & 0.91 \\
\hline & $5 \%$ & 0.67 & 0.88 & 0.98 \\
\hline & $10 \%$ & 0.82 & 0.96 & 0.99 \\
\hline \multirow[t]{3}{*}{ Model CB } & $1 \%$ & 0.15 & 0.10 & 0.72 \\
\hline & $5 \%$ & 0.38 & 0.50 & 0.90 \\
\hline & $10 \%$ & 0.54 & 0.69 & 0.95 \\
\hline \multirow{3}{*}{$\begin{array}{l}\text { Model CB } \\
\text { RESTRICTED }\end{array}$} & $1 \%$ & 0.70 & 0.87 & 0.98 \\
\hline & $5 \%$ & 0.88 & 0.99 & 1.00 \\
\hline & $10 \%$ & 0.94 & 0.99 & 1.00 \\
\hline
\end{tabular}

Note: The series are generated under an alternative hypothesis where each series is trend stationary with restricted structural change (model CB restricted):

$$
y_{t}=\mu+\beta t+\rho y_{t-1}+\gamma_{1} D U 1_{t}+\theta_{1} D T 1_{t}+\theta_{2} D T 2_{t}+\sum_{0}^{k} c_{i} \Delta y_{t-i}+\varepsilon_{t}
$$

For each of the data generating processes the coefficients are based on the previous estimations. Unit root tests are performed on these constructed series, tabulating how often the unit root null is (correctly) rejected. We use the bootstrapped critical values previously calculated and report results for tests of nominal size of $10 \%, 5 \%$ and $1 \%$. 
Table 9. Frequency of rejections

\begin{tabular}{|c|c|c|c|}
\hline Series & $\begin{array}{l}\text { Estimated } \\
\text { coefficients }\end{array}$ & $\begin{array}{l}\text { Significant } \\
\text { restricted } \\
\text { model }\end{array}$ & Probability $\left(\hat{\tau}<\hat{\tau}_{\text {samp }}\right)$ \\
\hline Real GNP & $\begin{aligned} \phi_{1} & =1.098976 \\
\phi_{2}= & -0.301937 \\
g & =0.029865 \\
\sigma_{v} & =0.030790 \\
\sigma_{u} & =0.065996\end{aligned}$ & $\begin{array}{l}\text { Model AA } \\
\text { Model CB }\end{array}$ & $\begin{array}{l}0.066 \\
0.170\end{array}$ \\
\hline Per-capita real GNP & $\begin{aligned} \phi_{1} & =1.096104 \\
\phi_{2} & =-0.300361 \\
g & =0.016476 \\
\sigma_{v} & =0.031414 \\
\sigma_{u} & =0.066548\end{aligned}$ & $\begin{array}{l}\text { Model AA } \\
\text { Model CC } \\
\text { Model CB }\end{array}$ & $\begin{array}{l}0.055 \\
0.286 \\
0.176\end{array}$ \\
\hline Employment & $\begin{aligned} \phi_{1} & =1.346522 \\
\phi_{2}= & -0.453280 \\
g & =0.016111 \\
\sigma_{v} & =0.027608 \\
\sigma_{u} & =0.032070\end{aligned}$ & $\begin{array}{l}\text { Model AA } \\
\text { Model CC }\end{array}$ & $\begin{array}{l}0.042 \\
0.149\end{array}$ \\
\hline GNP deflator & $\begin{aligned} \phi_{1} & =1.441533 \\
\phi_{2}= & -0.519504 \\
g & =0.020417 \\
\sigma_{v} & =0.024804 \\
\sigma_{u} & =0.058098\end{aligned}$ & Model CC & 0.505 \\
\hline Nominal wage & $\begin{aligned} \phi_{1} & =1.362966 \\
\phi_{2} & =-0.464419 \\
g & =0.040257 \\
\sigma_{v} & =0.017792 \\
\sigma_{u} & =0.067221\end{aligned}$ & Model CC & 0.755 \\
\hline Nominal GNP & $\begin{aligned} \phi_{1} & =1.440982 \\
\phi_{2} & =-0.519042 \\
g & =0.053131 \\
\sigma_{v} & =0.0337105 \\
\sigma_{u} & =0.088682\end{aligned}$ & $\begin{array}{l}\text { Model CC } \\
\text { Model CB }\end{array}$ & $\begin{array}{l}0.695 \\
0.303\end{array}$ \\
\hline
\end{tabular}

Note: The data is generated as a random walk with drift, characterized by large transitory fluctuations. Tests for a unit root in the presence of restricted structural change are performed on these constructed series. Each distribution is formed from 1000 realizations of the tests statistic calculated from 1000 simulated data samples generated from the particular model. 
Figure 1. Series which can be estimated with a specific model

\section{RESTRICTED MODELS}
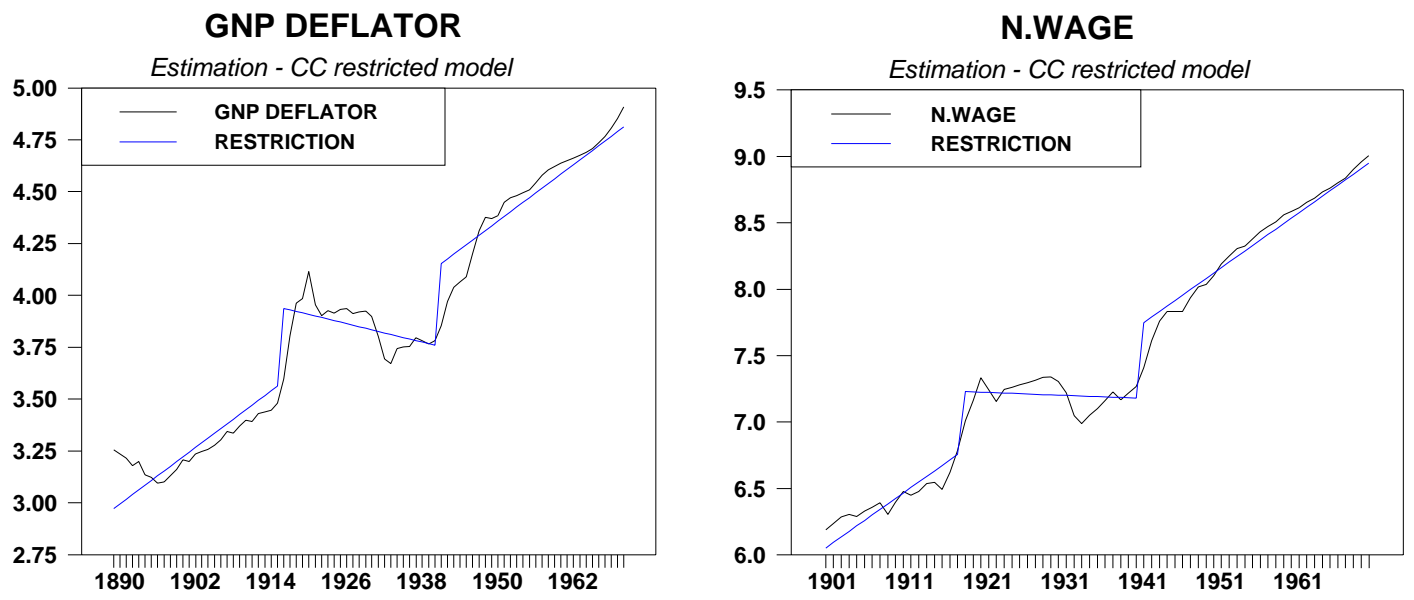

AA RESTRICTED MODEL EMPLOYMENT

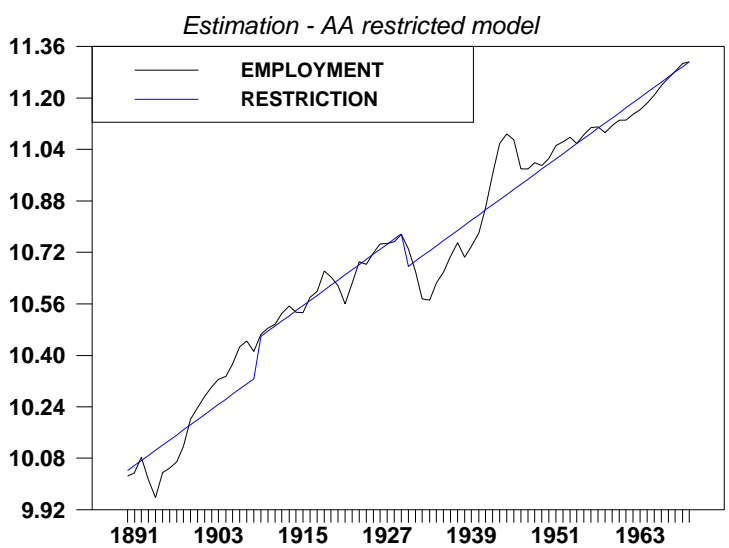

CB RESTRICTED MODEL

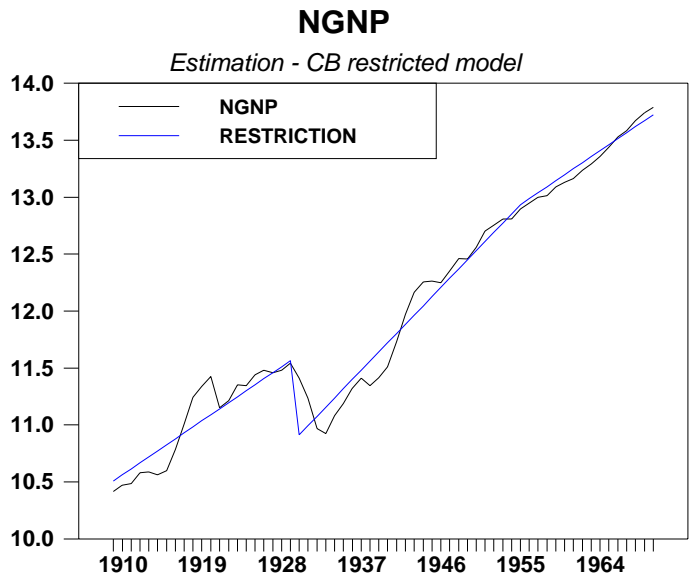

Note: Each series is represented in natural logarithms of the annual data. The solid line plots the series while the dashed line is the estimation of the restricted model. 
Figure 2. Series where we cannot make a distinction between AA and CB restricted models: RGNP and PCRGNP

RGNP

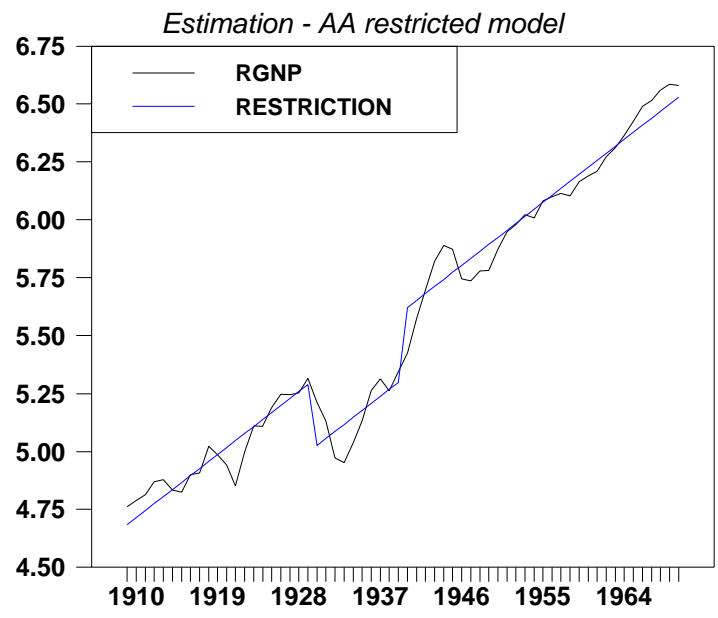

PCRGNP

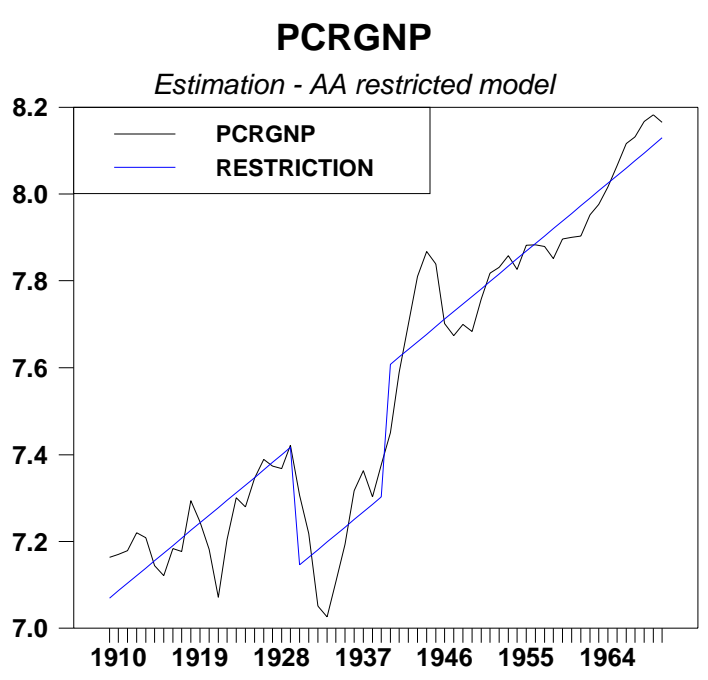

\section{RGNP}

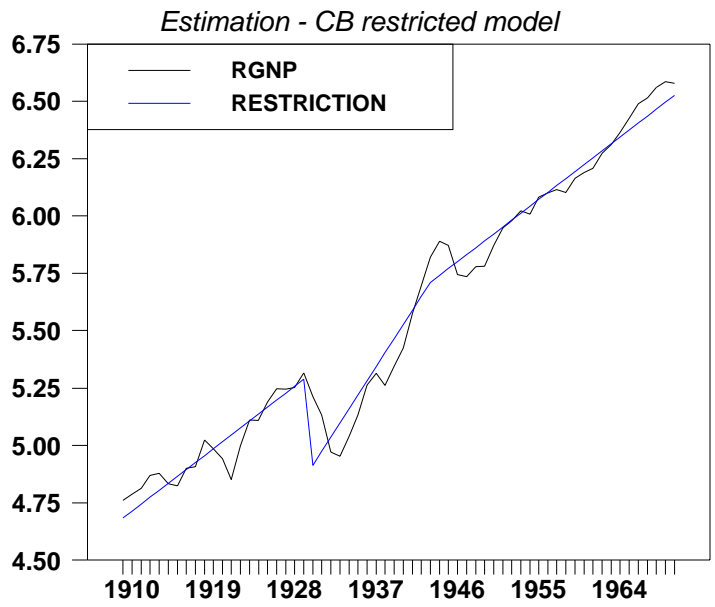

\section{PCRGNP}

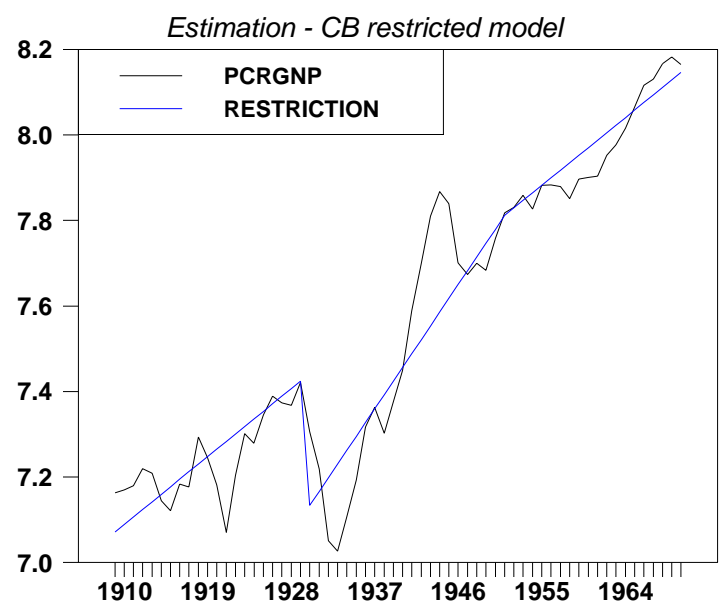

Note: Each series is represented in natural logarithms of the annual data. The solid line plots the series while the dashed line is the estimation of the restricted model. 